\title{
Age-stratified perioperative mortality after urological surgeries
}

\author{
Brendan Wallace $^{1}$; Rodney H. Breau ${ }^{1,2}$; Sonya Cnossen ${ }^{1}$; Christopher Knee ${ }^{1}$; Daniel \\ McIsaac $^{2,3}$; Ranjeeta Mallick ${ }^{2}$; Ilias Cagiannos ${ }^{1}$; Christopher Morash ${ }^{1}$; Luke T. \\ Lavallée $e^{1,2}$ \\ ${ }^{1}$ Division of Urology, Department of Surgery, The Ottawa Hospital, University of \\ Ottawa; ${ }^{2}$ Clinical Epidemiology Program, Ottawa Hospital Research Institute; ${ }^{3}$ Department of \\ Anesthesiology \& Pain Medicine, The Ottawa Hospital, University of Ottawa; Ottawa, ON, Canada
}

Cite as: Can Urol Assoc J 2018 April 6; Epub ahead of print. http://dx.doi.org/10.5489/cuaj.5022

\section{Published online April 6, 2018}

$* * *$

\section{Introduction}

Life expectancy in North America is increasing and more elderly patients are presenting for surgical consultations. ${ }^{1}$ Patient selection for surgery and optimal counselling requires data about procedure-specific risks and benefits. Age is a key variable for risk stratification, as older patients tend to experience more postoperative adverse events than younger patients.

Previous reports have characterized morbidity and mortality of urological procedures by age, with many focusing on outcomes of octogenarians because these patients may be considered ineligible for surgery by some providers on the basis of age alone. ${ }^{2-6}$ However, most of these studies are small, from a single centre, and examine only one procedure. Therefore, it is difficult to generalize their findings and find data that are broadly applicable and readily accessible in a clinical setting. A study by Patel et $\mathrm{al}^{7}$ used the American College of Surgeons National Surgical Quality Improvement Program (NSQIP) database to examine the relationship between age and morbidity in several urological procedures; however, they did not completely characterize the association between age and mortality for each procedure. ${ }^{7}$ Crude mortality rates are a common starting point for risk discussions with individual patients. Therefore, describing and understanding the association between age and mortality risk for specific urological procedures will help urologists counsel patients about their risk of death from surgery.

The primary objective of this study was to determine the risk of death at 30 days after common urological procedures by age group. The secondary objective was to compare mortality for open and laparoscopic surgical approaches. 


\section{Methods}

This was a historical cohort study of patients receiving urologic surgery captured in NSQIP. NSQIP is a prospective multicenter, international quality improvement program and contains data from over 700 hospitals. NSQIP records patient characteristics, treatment characteristics, details of surgery, and peri-operative morbidity and mortality up to 30 days post-operatively. Trained clinical abstractors at each participating site compile NSQIP data and previous audits have reported high reliability of the data ${ }^{8}$.

This study examined urologic surgeries commonly performed in elderly patients from January 2006 to December 2015. Current Procedural Terminology (CPT) codes were used to identify and group common procedures. The procedures selected for the study were nephroureterectomy (open; CPT 50234, 50236 and laparoscopic; CPT 50548), radial cystectomy with diversion (CPT 51570, 51575, 51580, 51585, 51590), percutaneous nephrolithotomy (PCNL) (CPT 50060, 50065), radical nephrectomy (open; CPT 50220, 50225, 50230 and laparoscopic; 50545, 50546), partial nephrectomy (open; CPT 50240 and laparoscopic; CPT 50543), prostatectomy (open; CPT 55840, 55842, 55845 and laparoscopic/robotic; 55866), transurethral resection of the prostate (TURP) (CPT 52601, 52630) and transurethral resection of bladder tumor(s) (TURBT) (CPT $52243,52235,52240)$. Patients had to be $>18$ years of age, no other exclusion criteria were applied. The number and proportion of patients receiving each procedure who died of any cause by 30 days post-operatively was determined.

Mortality rates were stratified by age group; less than 50, 50-59, 60-69, 70-79 and $>80$ years. Mortality was also stratified by surgical approach when applicable (open versus laparoscopic).

Interaction analyses were performed to determine if the effect of age category on mortality varied by procedure and surgical approach (laparoscopic vs. open). Multiplicative interaction terms agexprocedure and agexlaparoscopy were included in two separate binomial regression models using logit link.

NSQIP contains detailed risk modifying information for patient characteristics including International Classification of Disease (ICD) coded diagnosis, medical comorbidities, body mass index, renal function, previous treatments (e.g. chemotherapy, radiotherapy, etc.) and surgical factors (e.g. operating time, type of anesthesia, etc.). This study purposefully did not adjust for these factors because the objective was to provide estimates of overall mortality based on age alone. NSQIP does not include tumor factors such as stage or grade. Procedures that had less than 20 patients for a given age group are not reported because the small sample size may produce results that are not generalizable. Institutional ethics board approval was obtained from the Ottawa Hospital Research Ethics Board. SAS software version 9.4 for Windows was used for analyses (Cary, NC, USA). NSQIP hospitals are the source of data used in this analysis; however, NSQIP has not reviewed the methodology of this study and is not responsible for its content. 


\section{Results}

From 2006-2015 there were 124,262 eligible urologic procedures identified in NSQIP. The most common procedure was laparoscopic/robotic radical prostatectomy with 31,234 cases. Overall, $36 \%$ of patients were over 70 years of age and $12 \%$ were over 80 years of age. For some procedures, a small proportion of patients were over 80 years. For example, patients over 80 years comprised approximately 2.7 and 3.3\% of laparoscopic and open partial nephrectomy cases respectfully and 0.5 and $1.3 \%$ of laparoscopic and open radical prostatectomy cases respectfully. For other procedures, including TURBT, TURP, and laparoscopic nephroureterectomy, patients over 80 years comprised $30 \%$, $25 \%$, and $21 \%$ of cases, respectively. These differences are likely owing to the natural history of the disease being treated and the perceived risk associated with the procedure. No risk of mortality was reported for PCNL because the frequency of this procedure in NSQIP was low relative rendering the data on mortality imprecise and unreliable.

A total of $1,011(0.80 \%)$ patients died across all procedures by 30 days postoperatively. The procedure with the highest overall risk of mortality was open nephroureterectomy at $2.90 \%$ (Table 2). The procedure with the lowest overall risk of mortality was laparoscopic/robotic prostatectomy $(0.13 \%)$. In patients over 80 years, the procedures with the highest risk of mortality were open radical nephrectomy (5.32\%), open nephroureterectomy (4.90\%), and radical cystectomy with diversion (4.70\%). By comparison, each of these procedures had mortality rates under $1 \%$ in patients less than 50 years of age. Overall there was a trend of increasing mortality by age category in all urologic procedures examined (Table 2).

Use of a laparoscopic surgical approach was consistently associated with a lower risk of mortality compared to the same open procedure (Figure 1). For example, an open nephroureterectomy was associated with almost double the overall risk of mortality compared to laparoscopic nephroureterectomy ( $2.9 \%$ versus $1.56 \%$, respectively). This trend was observed over all age categories.

Tests for effect modification of age category by procedure and age category by surgical approach (laparoscopic vs. open) were not significant ( $>>0.05$ ). This indicates the effect of age category on mortality did not vary significantly based on the type of surgery or surgical approach used.

\section{Discussion}

This study examined absolute mortality rates at 30 days for urologic procedures commonly performed in elderly patients using NSQIP. As anticipated, a trend of increased mortality after surgery with increasing age category was identified: in all 11 procedures studied, mortality rates were highest in people aged 80 years and older. A lower risk of mortality for procedures performed laparoscopically was also demonstrated when compared to open. 
Common sense suggests that the risk of all-cause mortality after surgery should increase with age. Indeed, this and other studies have reported increased mortality after surgery by age in both urologic and non-urologic surgeries ${ }^{9,10}$. A plethora of patient and surgery-specific data are available in NSQIP for risk adjustment. Data for risk adjustment are important for comparing outcomes across hospitals, surgeons, and studies. This study purposefully did not adjust the risk of death using patient data available in NSQIP because the objective was to report crude mortality rates by age group. These data, as they are presented, could be rapidly used by clinicians as a starting point when having a discussion about mortality risk with their patients. It may be assumed that very healthy patients have lower mortality risks than their age category and patients with many comorbidities have higher risks than their age group if other surgical and disease factors remain equal. In appropriate circumstances, the clinician could then use patient specific data and a platform such as the NSQIP Surgical Risk Calculator to personalize risk estimates https://riskcalculator.facs.org/RiskCalculator/) ${ }^{11}$.

These data indicate that the mortality rate for almost all procedures increases significantly after age 80. In many cases, the risk of death in octogenarians is double the risk for patients age 70-79. Even less invasive procedures such as TURBT and TURP were associated with a high risk of mortality at 30 days in octogenarians (3.63 and 1.60\% respectively). These rates are comparable to open radical procedures such as cystectomy and nephrectomy in younger age groups. These data underscore the importance of counseling patients about risk because no surgical procedure should be approached lightly in elderly patients.

Patient selection for surgery by age differed significantly by procedure. For example, over $20 \%$ of patients receiving laparoscopic nephroureterectomy were over 80 years of age. This is likely because upper tract urothelial malignancy is aggressive and no alternate curative treatment option exists. In contrast, only three and one percent of patients receive partial nephrectomy and radical prostatectomy, respectively, after age 80 . This is likely because tumors treated by these procedures are more indolent or alternative treatments, such as radiotherapy for prostate cancer, are available.

A consistent decreased risk of mortality was observed across procedures when a laparoscopic approach was used. This observation may be explained by several factors. First, it is likely that, on average, tumors that are amenable to a laparoscopic approach are smaller (lower stage) and more easily resected than tumors requiring an open approach. Second, patients receiving open surgery may have other comorbidities or other disease factors precluding laparoscopy, such as previous radiation or surgery, which could make the dissection more challenging and increase mortality risk. Third, although laparoscopy is now a widely used technique for urologists, it is possible that surgeons performing laparoscopy work in different hospital settings than surgeons performing open surgery and that surgeon or system differences account for some differences in mortality. 
Therefor, these data do not prove that a laparoscopy lowers the risk of death after surgery, but rather the patient population who have tumor, disease, and treatment factors that result in laparoscopic surgery have lower death rates than those receiving open surgery.

Strengths of this study include the large sample size and multi-institutional data source, rendering outcomes generalizable. Most importantly, this study provides summary tables for rapid access to mortality outcomes by age group and procedure that can be used in a clinical setting. Currently, most available data are from single highvolume institutions and report on one or a few procedures. This study has several limitations. First, a 30-day post-operative window for mortality is a relatively short follow-up and some deaths related to surgery are not accounted for in the data. Second, an important limitation of the summary tables is that tumor grade/stage and patient comorbidities/previous treatments are not adjusted for, and these factors very likely have an impact on mortality risk. Therefor urologist may use these data as a starting point for counselling patients and refine risk estimated using additional patient/tumor/treatment data.

\section{Conclusion}

There is an increasing risk of mortality with age and with open surgical procedures in urology. These data can serve as a starting point to help urologists educate their patients about mortality risk with surgery. 


\section{References}

1. Etzioni DA, Liu JH, Maggard MA et al. The aging population and its impact on the surgery workforce. Ann Surg. 2003;238:170-77.

2. Halachmi S, Katz Y, Meretyk S, et al. Perioperative morbidity and mortality in 80 years and older undergoing elective urology surgery - a prospective study. Aging Male. 2008;11:162-66.

3. Liberman D, Lughezzani G, Sun M, et al. Perioperative mortality is significantly greater in septuagenarian and octogenarian patients treated with radical cystectomy for urothelial carcinoma of the bladder. Urology. 2011;77:660-66.

4. Berger J, Fardoun T, Brassart E, et al. Detailed analysis of morbidity following nephrectomy for renal cell carcinoma in octogenarians. J Urol. 2012;188:736-40.

5. Vasdev N, Hussein HK, Davidson A, et al. Radical renal surgery (laparoscopic and open) in octogenarians. Surg. 2011;9:135-41.

6. Elshal AM, Elmansy HM, Elhilali MM. Transurethral laser surgery for benign prostate hyperplasia in octogenarians: Safety and outcomes. Urology. 2013;81:634-639.

7. Patel HD, Ball MW, Cohen JE, et al. Morbidity of urological surgical procedures: An analysis of rates, risk factors, and outcomes. Urology. 2015;85:552-60.

8. Khuri SF, Daley J, Henderson W, et al. The Department of Veterans Affairs' NSQIP: the first national, validated, outcome-based, risk-adjusted, and peercontrolled program for the measurement and enhancement of the quality of surgical care. National VA Surgical Quality Improvement Program. Ann Surg. 1998;228:491-507.

9. Hamel M, Henderson W, Khuri S, et al. Surgical outcomes for patients aged 80 and older: Morbidity and mortality from major noncardiac surgery. J Am Geriatr Soc. 2005;53:424-29.

10. Polanczyk CA, Marcantonio E, Goldman L, et al. Impact of age on perioperative complications and length of stay in patients undergoing noncardiac surgery. Ann Intern Med. 2001;134:637-43.

11. American College of Surgeons National Surgical Quality Improvement Program. ACS NSQIP - Surgical Risk Calculator. https://riskcalculator.facs.org/RiskCalculator/PatientInfo.jsp. Published 2017. Accessed August 20, 2017. 
Figures and Tables

Fig. 1. Absolute risk of mortality for common urologic procedures using open and laparoscopic approaches. For each procedure the risk of death after surgery is lower in the patient population undergoing laparoscopic surgery $(\mathrm{p}<0.05)$. Note $y$-axis extends from 0 to $4 \%$ only.

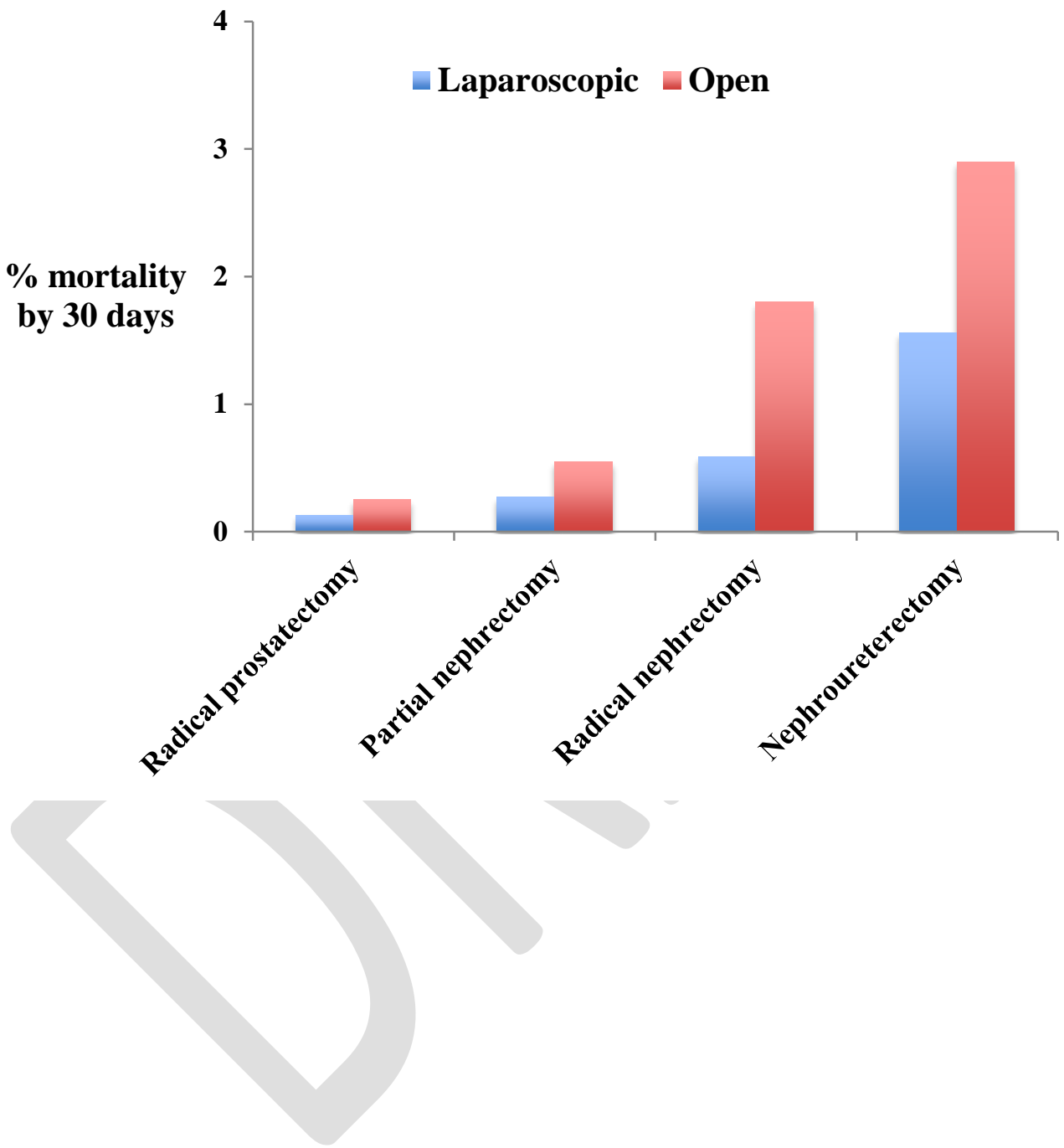




\begin{tabular}{|c|c|c|c|c|c|c|}
\hline Procedure & $\begin{array}{c}\text { Frequency } \\
\text { n }\end{array}$ & $\begin{array}{l}<50 \\
\text { n (\%) }\end{array}$ & $\begin{array}{l}50-59 \\
\text { n (\%) }\end{array}$ & $\begin{array}{l}\text { 60-69 } \\
\text { n (\%) }\end{array}$ & $\begin{array}{l}\text { 70-79 } \\
\text { n (\%) }\end{array}$ & $\begin{array}{l}\geq 80 \\
\text { n (\%) }\end{array}$ \\
\hline Lap radical prostatectomy & 31234 & $\begin{array}{l}1324 \\
(4.2)\end{array}$ & $\begin{array}{r}9667 \\
(31.0)\end{array}$ & $\begin{array}{l}15565 \\
(49.8)\end{array}$ & $\begin{array}{c}4512 \\
(14.5)\end{array}$ & $\begin{array}{l}166 \\
(0.5)\end{array}$ \\
\hline TURP & 25269 & $\begin{array}{c}314 \\
(1.2)\end{array}$ & $\begin{array}{l}2131 \\
(8.4)\end{array}$ & $\begin{array}{c}7382 \\
(29.2)\end{array}$ & $\begin{array}{c}9242 \\
(36.6)\end{array}$ & $\begin{array}{r}6200 \\
(24.5) \\
\end{array}$ \\
\hline TURBT & 15873 & $\begin{array}{l}634 \\
(4.0)\end{array}$ & $\begin{array}{l}1695 \\
(10.7)\end{array}$ & $\begin{array}{c}3929 \\
(24.8)\end{array}$ & $\begin{array}{l}4846 \\
(30.5)\end{array}$ & $\begin{array}{l}4769 \\
(30.0)\end{array}$ \\
\hline Lap radical nephrectomy & 11501 & $\begin{array}{c}2232 \\
(19.4)\end{array}$ & $\begin{array}{r}2637 \\
(22.9)\end{array}$ & $\begin{array}{c}3279 \\
(28.5)\end{array}$ & $\begin{array}{c}2381 \\
(20.7)\end{array}$ & $\begin{array}{c}972 \\
(8.5)\end{array}$ \\
\hline Lap partial nephrectomy & 9290 & $\begin{array}{r}2053 \\
(22.1)\end{array}$ & $\begin{array}{l}2469 \\
(26.6)\end{array}$ & $\begin{array}{r}2929 \\
(31.5)\end{array}$ & $\begin{array}{l}1584 \\
(17.1)\end{array}$ & $\begin{array}{c}255 \\
(2.7)\end{array}$ \\
\hline $\begin{array}{l}\text { Radical cystectomy with } \\
\text { diversion }\end{array}$ & 8011 & $\begin{array}{r}465 \\
(5.8)\end{array}$ & $\begin{array}{l}1269 \\
(15.8)\end{array}$ & $\begin{array}{c}2385 \\
(29.8)\end{array}$ & $\begin{array}{l}2808 \\
(35.1)\end{array}$ & $\begin{array}{l}1084 \\
(13.5)\end{array}$ \\
\hline Open radical prostatectomy & 7617 & $\begin{array}{l}244 \\
(3.2)\end{array}$ & $\begin{array}{l}2018 \\
(26.5)\end{array}$ & $\begin{array}{c}3889 \\
(51.1)\end{array}$ & $\begin{array}{l}1366 \\
(17.9)\end{array}$ & $\begin{array}{c}100 \\
(1.3)\end{array}$ \\
\hline Open radical nephrectomy & 7113 & $\begin{array}{c}1364 \\
(19.2) \\
\end{array}$ & $\begin{array}{l}1813 \\
(25.5)\end{array}$ & $\begin{array}{c}2136 \\
(30.0) \\
\end{array}$ & $\begin{array}{c}1349 \\
(19.0)\end{array}$ & $\begin{array}{r}451 \\
(6.3) \\
\end{array}$ \\
\hline Open partial nephrectomy & 5046 & $\begin{array}{l}1093 \\
(21.7) \\
\end{array}$ & $\begin{array}{l}1328 \\
(26.3) \\
\end{array}$ & $\begin{array}{c}1532 \\
(30.4) \\
\end{array}$ & $\begin{array}{c}929 \\
(18.4)\end{array}$ & $\begin{array}{c}164 \\
(3.3) \\
\end{array}$ \\
\hline Lap nephroureterectomy & 2249 & $\begin{array}{c}211 \\
(9.4) \\
\end{array}$ & $\begin{array}{c}310 \\
(13.8) \\
\end{array}$ & $\begin{array}{c}546 \\
(24.3) \\
\end{array}$ & $\begin{array}{c}713 \\
(31.7) \\
\end{array}$ & $\begin{array}{c}469 \\
(20.9) \\
\end{array}$ \\
\hline Open nephroureterectomy & 861 & $\begin{array}{c}114 \\
(13.2) \\
\end{array}$ & $\begin{array}{c}114 \\
(13.2) \\
\end{array}$ & $\begin{array}{c}245 \\
(28.5) \\
\end{array}$ & $\begin{array}{c}245 \\
(28.5) \\
\end{array}$ & $\begin{array}{c}143 \\
(16.6) \\
\end{array}$ \\
\hline Percutaneous nephrolithotomy & 198 & $\begin{array}{c}67 \\
(33.8) \\
\end{array}$ & $\begin{array}{c}60 \\
(30.3) \\
\end{array}$ & $\begin{array}{c}42 \\
(21.2) \\
\end{array}$ & $\begin{array}{c}26 \\
(13.1) \\
\end{array}$ & $\begin{array}{c}3 \\
(1.5) \\
\end{array}$ \\
\hline
\end{tabular}

Procedures are arranged by frequency of procedure. Lap: laparoscopic; TURBT:

transurethral resection of bladder tumour; TURP: transurethral resection of prostate. 


\begin{tabular}{|c|c|c|c|c|c|c|c|}
\hline Procedure & $\begin{array}{c}\text { Total } \\
\text { mortality } \\
\text { n (\%) }\end{array}$ & $\begin{array}{c}<50 \\
\text { n (\%) }\end{array}$ & $\begin{array}{l}50-59 \\
\text { n (\%) }\end{array}$ & $\begin{array}{l}\text { 60-69 } \\
\text { n (\%) }\end{array}$ & $\begin{array}{l}70-79 \\
\text { n (\%) }\end{array}$ & $\begin{array}{c}\geq 80 \\
\text { n (\%) }\end{array}$ & $\mathbf{p}$ \\
\hline $\begin{array}{l}\text { Lap partial } \\
\text { nephrectomy }\end{array}$ & $\begin{array}{c}25 \\
(0.27)\end{array}$ & $\begin{array}{c}2 \\
(0.10)\end{array}$ & $\begin{array}{c}2 \\
(0.08)\end{array}$ & $\begin{array}{c}7 \\
(0.24)\end{array}$ & $\begin{array}{c}10 \\
(0.63)\end{array}$ & $\begin{array}{c}4 \\
(1.57)\end{array}$ & $<0.01$ \\
\hline $\begin{array}{l}\text { Lap radical } \\
\text { nephrectomy }\end{array}$ & $\begin{array}{c}68 \\
(0.59)\end{array}$ & $\begin{array}{c}1 \\
(0.04)\end{array}$ & $\begin{array}{c}10 \\
(0.38)\end{array}$ & $\begin{array}{c}18 \\
(0.55)\end{array}$ & $\begin{array}{c}22 \\
(0.92)\end{array}$ & $\begin{array}{c}17 \\
(1.75)\end{array}$ & $<0.01$ \\
\hline $\begin{array}{l}\text { Lap radical } \\
\text { prostatectomy }\end{array}$ & $\begin{array}{c}40 \\
(0.13)\end{array}$ & $\begin{array}{c}0 \\
(0)\end{array}$ & $\begin{array}{c}11 \\
(0.11)\end{array}$ & $\begin{array}{c}17 \\
(0.11)\end{array}$ & $\begin{array}{c}9 \\
(0.20)\end{array}$ & $\begin{array}{c}3 \\
(1.81)\end{array}$ & $<0.01$ \\
\hline $\begin{array}{l}\text { Lap } \\
\text { nephroureterectomy }\end{array}$ & $\begin{array}{c}35 \\
(1.56)\end{array}$ & $\begin{array}{l}0 \\
(0)\end{array}$ & $\begin{array}{c}3 \\
(0.97)\end{array}$ & $\begin{array}{c}8 \\
(1.47)\end{array}$ & $\begin{array}{c}12 \\
(1.68)\end{array}$ & $\begin{array}{c}12 \\
(2.56)\end{array}$ & 0.12 \\
\hline $\begin{array}{l}\text { Open partial } \\
\text { nephrectomy }\end{array}$ & $\begin{array}{c}28 \\
(0.55)\end{array}$ & $\begin{array}{c}2 \\
(0.18)\end{array}$ & $\begin{array}{c}3 \\
(0.23)\end{array}$ & $\begin{array}{c}8 \\
(0.52)\end{array}$ & $\begin{array}{c}9 \\
(0.97)\end{array}$ & $\begin{array}{c}6 \\
(3.66)\end{array}$ & $<0.01$ \\
\hline $\begin{array}{l}\text { Open radical } \\
\text { nephrectomy }\end{array}$ & $\begin{array}{c}128 \\
(1.80)\end{array}$ & $\begin{array}{c}13 \\
(0.95)\end{array}$ & $\begin{array}{c}20 \\
(1.10)\end{array}$ & $\begin{array}{c}30 \\
(1.40)\end{array}$ & $\begin{array}{c}41 \\
(3.04)\end{array}$ & $\begin{array}{c}24 \\
(5.32)\end{array}$ & $<0.01$ \\
\hline $\begin{array}{l}\text { Open radical } \\
\text { prostatectomy }\end{array}$ & $\begin{array}{c}19 \\
(0.25)\end{array}$ & $\begin{array}{c}0 \\
(0)\end{array}$ & $\begin{array}{c}3 \\
(0.15)\end{array}$ & $\begin{array}{c}8 \\
(0.21)\end{array}$ & $\begin{array}{c}6 \\
(0.44)\end{array}$ & $\begin{array}{c}2 \\
(2.00)\end{array}$ & $<0.01$ \\
\hline $\begin{array}{l}\text { Open } \\
\text { nephroureterectomy }\end{array}$ & $\begin{array}{c}25 \\
(2.90)\end{array}$ & $\begin{array}{c}1 \\
(0.88)\end{array}$ & $\begin{array}{c}1 \\
(0.88)\end{array}$ & $\begin{array}{c}5 \\
(2.04)\end{array}$ & $\begin{array}{c}11 \\
(4.49)\end{array}$ & $\begin{array}{c}7 \\
(4.90)\end{array}$ & 0.09 \\
\hline $\begin{array}{l}\text { Radical cystectomy } \\
\text { with diversion }\end{array}$ & $\begin{array}{c}189 \\
(2.36)\end{array}$ & $\begin{array}{c}4 \\
(0.86)\end{array}$ & $\begin{array}{c}17 \\
(1.34)\end{array}$ & $\begin{array}{c}39 \\
(1.64)\end{array}$ & $\begin{array}{c}78 \\
(2.78)\end{array}$ & $\begin{array}{c}51 \\
(4.70)\end{array}$ & $<0.01$ \\
\hline TURBT & $\begin{array}{c}283 \\
(1.78)\end{array}$ & $\begin{array}{c}5 \\
(0.79)\end{array}$ & $\begin{array}{c}16 \\
(0.94)\end{array}$ & $\begin{array}{c}30 \\
(0.76)\end{array}$ & $\begin{array}{c}59 \\
(1.22)\end{array}$ & $\begin{array}{c}173 \\
(3.63)\end{array}$ & $<0.01$ \\
\hline TURP & $\begin{array}{c}166 \\
(0.66)\end{array}$ & $\begin{array}{c}0 \\
(0)\end{array}$ & $\begin{array}{c}4 \\
(0.19)\end{array}$ & $\begin{array}{c}23 \\
(0.31)\end{array}$ & $\begin{array}{c}40 \\
(0.43)\end{array}$ & $\begin{array}{c}99 \\
(1.60)\end{array}$ & $<0.01$ \\
\hline
\end{tabular}

Lap: laparoscopic; TURBT: transurethral resection of bladder tumour; TURP: transurethral resection of prostate. 